\title{
Unusual conservation among genes encoding small secreted salivary gland proteins from a gall midge
}

Ming-Shun Chen ${ }^{1,2^{*}}$, Xuming Liư ${ }^{2}$, Ziheng Yang ${ }^{3}$, Huixian Zhao ${ }^{4}$, Richard H Shukle ${ }^{5}$, Jeffrey J Stuart ${ }^{5}$, Scot Hulbert ${ }^{6}$

\begin{abstract}
Background: In most protein-coding genes, greater sequence variation is observed in noncoding regions (introns and untranslated regions) than in coding regions due to selective constraints. During characterization of genes and transcripts encoding small secreted salivary gland proteins (SSSGPS) from the Hessian fly, we found exactly the opposite pattern of conservation in several families of genes: the non-coding regions were highly conserved, but the coding regions were highly variable.

Results: Seven genes from the SSSGP-1 family are clustered as one inverted and six tandem repeats within a $15 \mathrm{~kb}$ region of the genome. Except for SSSGP-1A2, a gene that encodes a protein identical to that encoded by SSSGP-1A1, the other six genes consist of a highly diversified, mature protein-coding region as well as highly conserved regions including the promoter, 5'- and 3'-UTRs, a signal peptide coding region, and an intron. This unusual pattern of highly diversified coding regions coupled with highly conserved regions in the rest of the gene was also observed in several other groups of SSSGP-encoding genes or cDNAs. The unusual conservation pattern was also found in some of the SSSGP cDNAs from the Asian rice gall midge, but not from the orange wheat blossom midge. Strong positive selection was one of the forces driving for diversification whereas concerted homogenization was likely a mechanism for sequence conservation.

Conclusion: Rapid diversification in mature SSSGPs suggests that the genes are under selection pressure for functional adaptation. The conservation in the noncoding regions of these genes including introns also suggested potential mechanisms for sequence homogenization that are not yet fully understood. This report should be useful for future studies on genetic mechanisms involved in evolution and functional adaptation of parasite genes.
\end{abstract}

\section{Background}

Insect salivary glands are the main organs for producing proteins that are injected into hosts [1]. Plant-feeding insects, especially those with sucking mouthparts, inject proteins and other substances into host plants to facilitate mouthpart penetration, partially digest food before ingestion, and suppress plant defense [2-4]. Substances, including proteins with regulatory roles that can alter host physiology, are referred to as effectors [5]. Pathogens, including bacteria, fungi, oomycetes, and nematodes, deliver various effector proteins into host tissues [5-8]. Substantial evidence suggests that some of the

\footnotetext{
* Correspondence: ming-shun.chen@ars.usda.gov

'USDA-ARS, Hard Winter Wheat Genetics Research Unit, 4008 Throckmorton

Hall, Kansas State University, Manhattan, KS 66506, USA

Full list of author information is available at the end of the article
}

salivary proteins injected into host plants by insects also act as effectors to suppress defense and/or reprogram physiological pathways of host plants [3,5,9-12]. Gall midges (Cecidomyiidae), a large family of plant-feeding insects, apparently secrete effectors into host tissues, inducing various forms of plant outgrowth (galls) and altering other aspects of host physiology $[13,14]$. Plant galls contain a zone of "metabolic habitat modification" in which the parasite experiences a selective advantage because of enhanced nutrition and reduced plant defense [15]. Several organic compounds and enzymes injected into host plants by galling insects have been identified, including amino acids, auxin, proteases, oxidases, and pectinases [13], but the general composition of the proteins delivered into host plants by gall midges has not yet been fully characterized. 
The Hessian fly, Mayetiola destructor, is the most destructive insect pest of wheat worldwide [16]. Because of its importance in agriculture, intriguing behavior, ease of maintenance in culture, and relatively wellcharacterized genetics, Hessian fly is becoming a model species for studying insect-plant interactions $[17,18]$. Hessian fly does not induce the formation of an outgrowth gall, but nutritive cells with similarity to those inside macroscopic galls are formed at the larval feeding site [19]. Larvae do not cause extensive tissue damage to host plants, with their specialized mandibles making only a pair of small holes $[19,20]$. Nevertheless, wheat plants become permanently and irreversibly stunted after 4-5 days of feeding by a single larva [9]. Even if larvae are removed, growth of wheat seedlings cannot be restored $[9,20]$, suggesting that larvae inject substances into host plants that dramatically alter biochemical and physiological pathways of the attacked plant $[21,22]$.

As the first step to identify some of those proteins that are injected into host plants, we have previously generated numerous ESTs from cDNAs derived from dissected salivary glands of Hessian fly first instar larvae $[23,24]$. The majority of the salivary gland transcripts encode small proteins (50 to 200 amino acids) with typical secretion signal peptides at the $\mathrm{N}$-termini. We refer to these proteins as "small secreted salivary gland proteins" (SSSGPs). Here we report unusual conservation patterns of SSSGP-encoding genes and we discuss potential mechanisms for gene evolution and functional adaptation.

\section{Results and Discussion}

Unconventional conservation of SSSGP-encoding genes

The SSSGP-1 gene family includes seven members and is clustered as one inverted and six tandemly repeated genes within a $15 \mathrm{~kb}$ region of the genome (Figure $1 \mathrm{~A})$. The predicted structures of the genes were verified by comparing the genomic sequences with cDNA clones corresponding to genes SSSGP-1A, SSSGP-1B1, SSSGP-1C1 and SSSGP$1 D 1$ (a cDNA for SSSGP-1E1 has yet to be identified). All seven genes have a common structure, including a conserved putative promoter region, a 5'-untranslated region (5'-UTR), a signal peptide-coding region (SPCR), an intron, a mature protein-coding region (MPCR), and a 3'-untranslated region (3'-UTR; Figure 1B). Intergenic regions are small, ranging from 0.2 to $1 \mathrm{kB}$ (Genbank accession: GU196316). Among the seven genes, SSSGP$1 A 2$, present in the inverted repeat, was apparently recently duplicated and encodes an identical protein with SSSGP-1A1. The other six genes consist of highly diversified MPCRs as well as highly conserved regions, including the promoter region, 5'- and 3'-UTRs, SPCR, and the intron (Figure 1B, Additional file 1, Figure S1A). The predicted proteins are almost identical in their putative signal peptides, but share little similarity among the mature proteins (Figure 1C). This extreme pattern of diversification in MPCR, which we refer to here as super-diversification, coupled with strong conservation in other regions was also observed in several other groups of SSSGP-encoding genes (Additional file 1, Figure S1) or cDNAs from Hessian fly (Table 1, Additional file 2, Figure S2).

Except for the common features of diversification/conservation, there are no noticeable sequence or structural similarities between the different groups of SSSGP genes, and no apparent sequence similarities could be detected among different groups with currently available alignment methods such as BLAST. Most groups of SSSGP genes contain one intron (Additional file 1, Figures S1A, S1C, S1D). However, one group lacks introns (Additional file 1, Figure S1B) and several other groups contain multiple introns (Additional file 1, Figure S1E). For those genes containing introns, the first (or the sole) intron is located either at the boundary between the SPCR and MPCR, or within the SPCR (Additional file 1, Figure S1). The positions of intron/ exon boundaries are generally conserved among members within a group. However, deletions or shifts in intron/exon boundaries occur in gene groups with multiple introns (Additional file 1, Figure S1E). For all gene groups, multiple members in each group are clustered within short chromosome regions in the Hessian fly genome (Additional file 3, Figure S3).

To determine if such a genetic phenomenon exists in other gall midges, a similar analysis of salivary gland cDNAs was conducted on two other related insects, the orange wheat blossom midge (Sitodiplosis mosellana) and the Asian rice gall midge (Orseolia oryzae). Approximately 8,500 cDNAs from the wheat blossom midge and 3,500 from the Asian rice gall midge were sequenced. In each case, a similar proportion (45-50\%) of cDNA clones was found encoding different SSSGPs. Forty-eight different groups of putative SSSGPs were identified from the wheat blossom midge while 25 different groups of putative SSSGPs were identified from the Asian rice gall midge. Comparative analysis revealed that cDNAs and their encoded proteins from the Asian rice midge, wheat blossom midge, and Hessian fly were typically found to be species-specific; cDNAs from one species shared no detectable sequence similarity with those from the other two species, consistent with the rapidly evolving nature of SSSGP-encoding genes. The species-specific nature of SSSGP-encoding genes was further confirmed by PCR and by Southern blot analysis. No PCR amplification could be achieved using primer pairs designed according to cDNAs from another species. Similarly, no cross hybridization could be observed on Southern blots using cDNA probes from a different species (data not shown). The typical unconventional conservation pattern of 


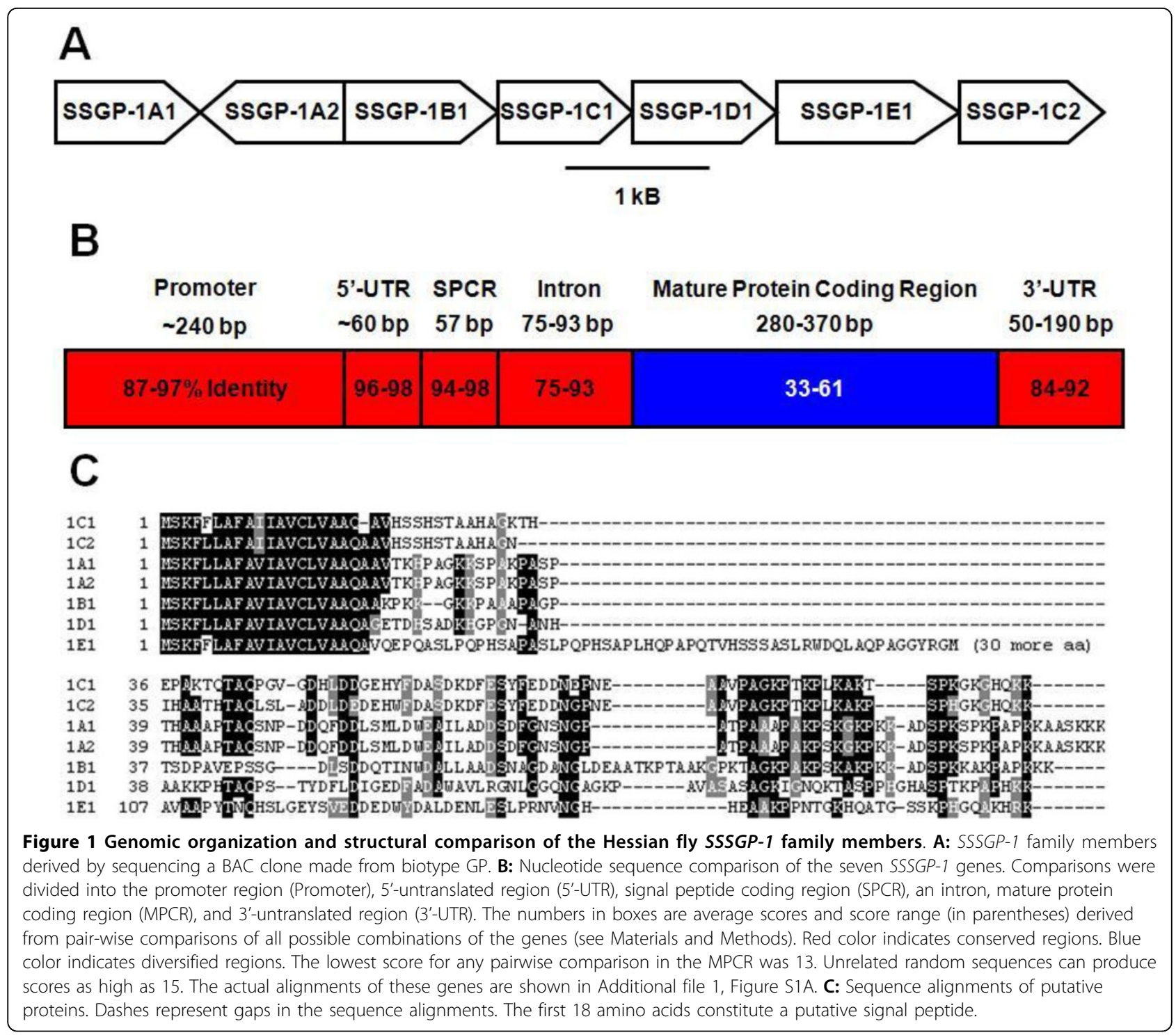

SSSGP-encoding genes observed in Hessian fly was also found in some of the SSSGP-encoding transcripts of the Asian rice midge (Additional file 2, Figure S2G), but not in any transcripts of the wheat blossom midge. This observation indicates that the unconventional conservation of SSSGP-encoding genes might be linked to adaption to environmental changes such as a change in host plants. Even though they live on different plant species, the Asian rice midge and Hessian fly larvae share a similar feeding mechanism. Larvae of both species feed on the meristem of a leaf-sheath within a plant, and their survival strictly depends on their ability to induce the formation of nutritive cells of plant tissue at the feeding site, to inhibit plant growth, and to suppress host defense $[17,19,25]$. Wheat blossom midges, on the other hand, feed on developing wheat seeds and either do not require extensive manipulation of host plants such as growth inhibition [19], or manipulate host plants in different ways.

Several genes from different mosquito species have been found encoding diverse secreted salivary proteins and some of these genes are also organized as tandem repeats [26]. Diverse toxic small peptides have been found in the venoms of predatory cone snails [27]. However, the extreme cases described here with a very short (100 to $500 \mathrm{bp}$ ), highly diversified segment followed by a very short $(\sim 500 \mathrm{bp})$, highly conserved segment arranged as multiple tandem repeats has not been found in any other organisms.

\section{Strong positive selection on SSSGP loci and alleles}

Strong positive (diversifying) selection appears to be one of the forces driving diversifications in MPCRs. Highly diversified members with less than $80 \%$ sequence identity 
Table 1 Similarity of different regions among cDNAs from different gene groups

\begin{tabular}{|c|c|c|c|c|c|c|c|c|c|c|c|c|c|}
\hline \multirow[t]{2}{*}{$\begin{array}{l}\text { Gene } \\
\text { group }\end{array}$} & \multirow[t]{2}{*}{$\begin{array}{l}\text { No. of } \\
\text { Seq. }\end{array}$} & \multicolumn{3}{|c|}{$\begin{array}{l}5^{\prime}-\text { Untranslated } \\
\text { region (5'-UTR) }\end{array}$} & \multicolumn{3}{|c|}{$\begin{array}{l}\text { Signal peptide coding } \\
\text { region (SPCR) }\end{array}$} & \multicolumn{3}{|c|}{$\begin{array}{l}\text { Mature protein coding } \\
\text { region (MPCR) }\end{array}$} & \multicolumn{3}{|c|}{$\begin{array}{l}\text { 3'-untranslated } \\
\text { region (3'-UTR) }\end{array}$} \\
\hline & & Length & $\begin{array}{l}\text { Score } \\
\text { AVE }\end{array}$ & $\begin{array}{l}\text { Score } \\
\text { range }\end{array}$ & Length & $\begin{array}{l}\text { Score } \\
\text { AVE }\end{array}$ & $\begin{array}{l}\text { Score } \\
\text { range }\end{array}$ & Length & $\begin{array}{l}\text { Score } \\
\text { AVE }\end{array}$ & $\begin{array}{l}\text { Score } \\
\text { range }\end{array}$ & Length & $\begin{array}{l}\text { Score } \\
\text { AVE }\end{array}$ & $\begin{array}{l}\text { Score } \\
\text { range }\end{array}$ \\
\hline SSSGP-1 & 6 & $58-59$ & 92 & $87-98$ & 57 & 94 & $92-98$ & $252-484$ & 49 & $13-100$ & $186-258$ & 88 & $79-94$ \\
\hline SSSGP-2 & 15 & $6-198$ & 84 & $52-100$ & 60 & 87 & $78-95$ & $258-462$ & 10 & $3-57$ & $77-269$ & 81 & $57-92$ \\
\hline SSSGP-3 & 4 & $31-36$ & 87 & $80-100$ & 54 & 80 & $70-96$ & $189-312$ & 22 & $6-71$ & $64-210$ & 73 & $49-98$ \\
\hline SSSGP-4 & 7 & $37-47$ & 94 & $83-100$ & 75 & 80 & $58-93$ & $360-636$ & 10 & $4-27$ & $121-222$ & 52 & $14-82$ \\
\hline SSSGP-5 & 3 & $81-87$ & 94 & $93-95$ & 69 & 96 & $95-97$ & $4-279$ & 15 & $11-19$ & $71-124$ & 65 & $48-85$ \\
\hline SSSGP-6 & 2 & $24-25$ & 87 & 87 & 63 & 95 & 95 & $249-255$ & 79 & 79 & $57-60$ & 91 & 91 \\
\hline SSSGP-31 & 4 & $52-65$ & 93 & $88-97$ & 39 & 97 & $94-100$ & $213-330$ & 16 & $8-28$ & $90-122$ & 92 & $85-96$ \\
\hline
\end{tabular}

Score average (AVE) and score range were derived by pair-wise comparison (Materials and Methods). Except for the two members from group SSSGP-6, the score average for MPCR is at least $40 \%$ less than those for other regions. The two members from group SSSGP-6 are likely relatively recent duplicates since they share an overall $83 \%$ sequence identity. The score average for these two members is $13 \%$ less than those for other regions.

within MPCRs did not produce meaningful alignments for analyzing nonsynonymous to synonymous substitution ratio $(d N / d S)$, but the fact that the coding regions are hard to align is itself evidence for fast evolution by positive selection or other mechanisms such as Y-family polymerases [28]. Analysis of moderately diversified group members with 80 to $95 \%$ sequence identity in their MPCRs all yielded $d N / d S$ above one (Table 2, Additional file 4, Figure S4). One pair of group members produced a $d N / d S$ ratio above 18 , indicating very strong positive selection. Due to the small size, similar sequences with greater than $95 \%$ sequence identity within MPCRs did not possess sufficient nucleotide substitutions to confidently discern evolutionary patterns through analyzing $d N / d S$. However, a different analysis of similar sequences derived from different alleles also produced strong evidence for positive selection (below).

Multiple transcripts corresponding to genes SSSGP1A1, SSSGP-1B1, and SSSGP-1C1 were isolated from three different Hessian fly populations. These different transcripts were likely derived from different alleles since evidence from in situ hybridization, Southern blots with genomic and BAC DNA samples, and primer specific PCR suggests a single locus for this gene family (Additional file 5, Figure S5). The ratio between nonsynonymous and synonymous substitutions was 1.5 or more within the MPCR, but less than 0.9 in the SPCR (Table 3, Additional files 6 and 7), again indicating positive selection in MPCRs for different alleles.

Evidence for positive selection is not common but has been demonstrated at several different types of genes controlling interactions between organisms that are mediated by molecular recognition. Typical examples are defenserelated genes including the major histocompatibility complex [29], immunoglobulins [30], defensins [31], plant resistance genes [32], plant chitinase genes [33], and pathogen effector genes [34]. The strong positive selection observed in SSSGP-encoding genes indicated that SSSGPs are also likely involved in interactions between Hessian fly and other organisms. Considering that Hessian fly larvae live within host plants, some of these SSSGPs may be secreted into host plants as effector proteins with a role in the insect's virulence. In plant-herbivore interactions, successful pathogens and parasitic arthropods not only require a large number of genes coding for effector proteins to suppress innate defense of host plants [35], but also require the ability to change this arsenal in response to shifts in the host population [36]. Evolution of plant populations in parasite recognition and surveillance systems thus provides strong selection for counter changes in effector proteins

Table 2 Evidence for positive selection on SSSGP group members

\begin{tabular}{llllll}
\hline Group & cDNA pair & Codon & dN/dS & dN \pm SE & dS \pm SE \\
\hline SSSGP-1 & 1C1/1C2 & 85 & 1.32 & $0.11 \pm 0.03$ & $0.08 \pm 0.04$ \\
\hline SSSGP-2 & G19B4/S21C6 & 122 & 9.43 & $0.12 \pm 0.02$ & $0.01 \pm 0.01$ \\
\hline SSSGP-2 & G10H7/G14E6 & 129 & 3.59 & $0.08 \pm 0.02$ & $0.02 \pm 0.01$ \\
\hline SSSGP-2 & L4C4/G28G12 & 78 & 1.12 & $0.22 \pm 0.04$ & $0.20 \pm 0.07$ \\
\hline SSSGP-4 & G13E6/G22C4 & 127 & 1.21 & $0.10 \pm 0.02$ & $0.08 \pm 0.04$ \\
\hline SSSGP-4 & G2C8/L4H12 & 173 & 1.46 & $0.14 \pm 0.02$ & $0.10 \pm 0.03$ \\
\hline SSSGP-4 & G16C10/G29D6 & 156 & 2.49 & $0.26 \pm 0.03$ & $0.11 \pm 0.03$ \\
\hline SSSGP-4 & G9B3/L1C12 & 179 & 1.52 & $0.13 \pm 0.02$ & $0.09 \pm 0.03$ \\
\hline SSSGP-6 & G7H5/G8C4 & 81 & 2.92 & $0.31 \pm 0.05$ & $0.11 \pm 0.05$ \\
\hline SSSGP-7 & G10C11/G15G6 & 119 & 1.48 & $0.11 \pm 0.02$ & $0.07 \pm 0.03$ \\
\hline SSSGP-10 & G8C1/G14G1 & 75 & 2.51 & $0.18 \pm 0.04$ & $0.07 \pm 0.03$ \\
\hline SSSGP-26 & G4C3/S22E4 & 162 & 5.67 & $0.04 \pm 0.01$ & $0.00 \pm 0.00$ \\
\hline SSSGP-31 & G7D10/S4A9 & 100 & 1.82 & $0.06 \pm 0.02$ & $0.03 \pm 0.03$ \\
\hline SSSGP-37 & S5E9/G9G9 & 41 & 2.51 & $0.11 \pm 0.04$ & $0.04 \pm 0.04$ \\
\hline SSSGP-79 & S14G9/S22D12 & 63 & 18.8 & $0.19 \pm 0.04$ & $0.01 \pm 0.01$ \\
\hline SSSGP-80 & L7H8/S8C9 & 123 & 1.84 & $0.04 \pm 0.01$ & $0.03 \pm 0.02$ \\
\hline SN/dS & Wet0
\end{tabular}

$\mathrm{dN} / \mathrm{dS}$ ratio were obtained by comparing MPCRs using PAML42 [53]. 
Table 3 Evidence for positive selection on different alleles (Additional file 6, Figure S6)

\begin{tabular}{lllllllll}
\hline Gene & \multicolumn{3}{l}{ Total cDNAs sequenced } & & Unique & Unique & \multicolumn{2}{l}{ Nonsyn/Syn } \\
\hline SSSGP-1A1 & GP & L & S & Total & CDNAs & proteins & SPCR & MPCR \\
\hline SSSGP-1B1 & 106 & 24 & 36 & 166 & 66 & 27 & $0.83(5 / 6)$ & $1.56(28 / 18)$ \\
\hline SSSGP-1C1 & 27 & 5 & 12 & 44 & 20 & 14 & $0.80(4 / 5)$ & $1.50(21 / 14)$ \\
\hline RPs & 157 & 34 & 23 & 214 & 96 & 47 & N/A & $2.33(21 / 9)$ \\
\hline
\end{tabular}

cDNAs were derived from three Hessian fly populations: biotype GP, biotype L, and a Syrian population (S). As a control, cDNAs coding for 26 different ribosomal proteins (RPs) that were isolated along with SSSGP cDNAs were included in this analysis. Sequence alignments for different SSSGP cDNAs are shown in Additional file 6, Figure S6 whereas alignments for RP CDNAs are shown in Additional file 7, Figure S7. "Nonsyn/Syn" represents the ratios of non-synonymous against synonymous substitutions in SPCR and MPCR, respectively.

from parasites [36,37]. The Hessian fly has been very successful in adaptation to changes in host plant populations [16,17]. The super-diversification in SSSGP genes may have provided the genetic basis for the development of counter-resistance in Hessian fly in response to changes in host plants.

\section{Concerted homogenization of noncoding regions}

Very strong selection for divergence could account for rapid divergence of MPCR but the high homology of the other regions of the genes is difficult to explain. Recombination between gene-family members, particularly those arranged in tandem arrays, acts to homogenize their sequences so they evolve in a concerted fashion $[38,39]$. Typically, however, this homogenization occurs throughout the whole gene and even the intergenic regions, not just specific domains in the genes. While crossover events would tend to homogenize the whole array, smaller gene conversion events might homogenize smaller regions. Little is known about recombination in gall midges, but conversion tracts at the Rosey locus of Drosophila have been found to be in the order of a few hundred base pairs [40]. Differences in sequence affinity among the various sub-regions of the SSSGP-1 family members corroborate frequent recombination in short DNA regions during Hessian fly evolution (Figure 2). The homogenization could be confined to termini of the genes if the conversion events were initiated near the ends of the genes or in intergenic regions. The nature of recombination hotspots varies between species [41], but they are commonly initiated intergenically [42], possibly at specific sequence motifs [43] or regulatory regions. Sequence heterogeneity in the MPCR due to strong positive selection could, in turn, affect the length of conversion tracks or how the recombination intermediates are resolved; conversion or crossover events [44]. If the sequence homogeneity of the SSSGP-encoding families was caused by concerted evolution from short conversion tracks initiated in the flanking regions, one would expect introns in the middle of the larger genes to be less homogenized. This is in fact what was observed in the SSSGP-2 family; noticeably, several introns (introns 22, 23, 26, 27, 35, 36, 37) were rearranged or deleted (Additional file 1, Figure S1E). The coding regions of the two SSSGP-2 family members correspond to approximately 950 nucleotides with 35 introns.

To explore whether functional adaptation might explain conservation of certain regions of gene families [45], we analyzed the patterns of transcript levels corresponding to specific genes under different conditions (Figure 3). In general, SSSGPs with higher sequence similarity in the promoter regions had more similar patterns of gene expression (Figures 2, 3). SSSGP-1A1, SSSGP-1A2, SSSGP-1B1, and SSSGP-1C1, whose promoters were very similar (Figure. $2 \mathrm{C}$ ), also exhibited similar expression patterns among tissues (Figure 3A) and developmental stages (Figure 3B), and among insects interacting with different plant genotypes (Figure 3C). The promoters of SSSGP-1C2, and SSSGP-1E1 were also similar to each other (Figure 2C), and these two genes also exhibited similar transcription patterns. However, the genes in the first group (SSSGP-1A1, SSSGP-1A2, SSSGP-1B1, and SSSGP-1C1) and the second group (SSSGP-1C2 and SSSGP-1E1) had strikingly different expression patterns (Figure 3). Small differences in the transcription patterns among members in the same promoter group were also observed. For example, SSSGP$1 C 2$ was expressed abundantly in 0.5 -day old larvae (Figure 3B, 1C2), whereas little SSSGP-1E1 expression was observed in the same larvae (Figure 3B, 1E1). These differences could indicate that small differences in the promoter (or other regulatory elements in other regions) of the genes can fine-tune the level of transcripts to satisfy specific requirements. These observations suggest that the conservation/diversification of the promoter regions has been strictly driven by functional adaptation.

The homogenization of 5'- and possibly even 3'-UTRs may also have a functional basis. Because UTRs play critical roles in post-transcriptional regulation of gene expression [46,47], we speculate that the SSSGP UTRs are critical for proper post-transcriptional regulation. For example, part of the conserved UTRs could serve as elements for binding with regulatory proteins or as 


\section{Full Length Genes}

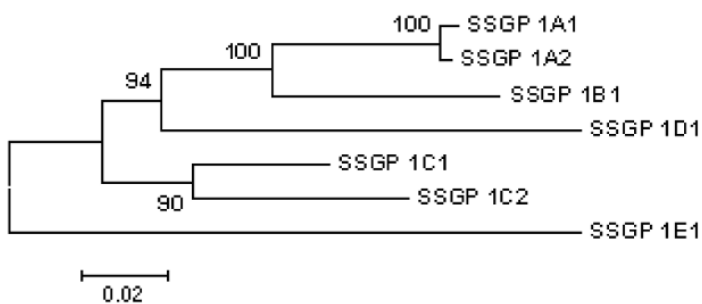

Promoter Regions

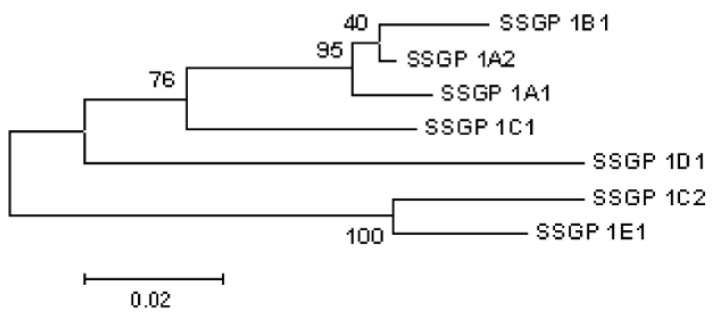

\section{Introns}

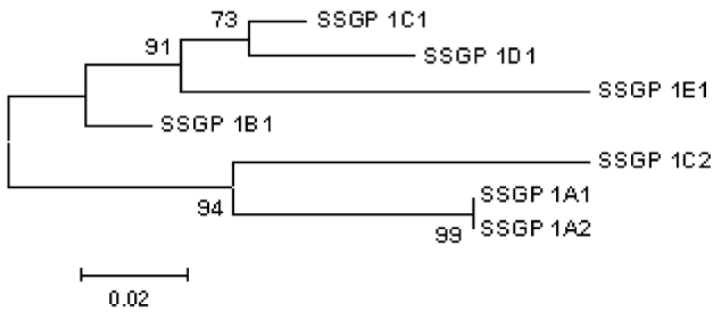

\section{MPCRs}

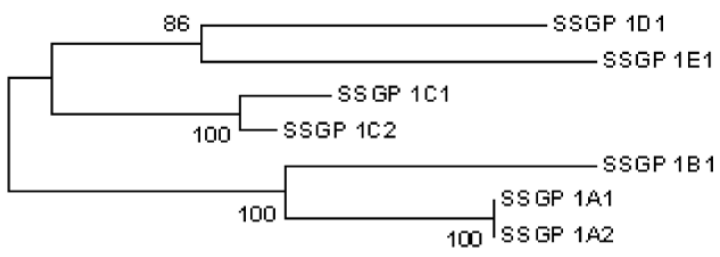

$\longmapsto$
Full Length Proteins

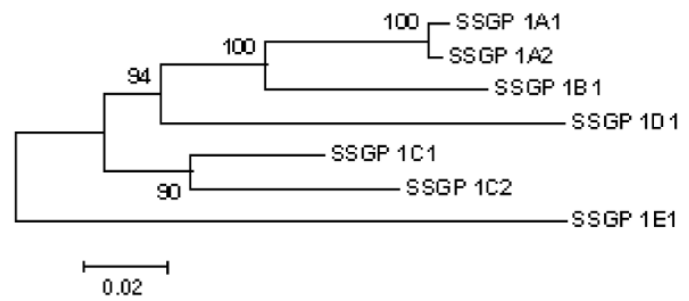

5 '-UTRs

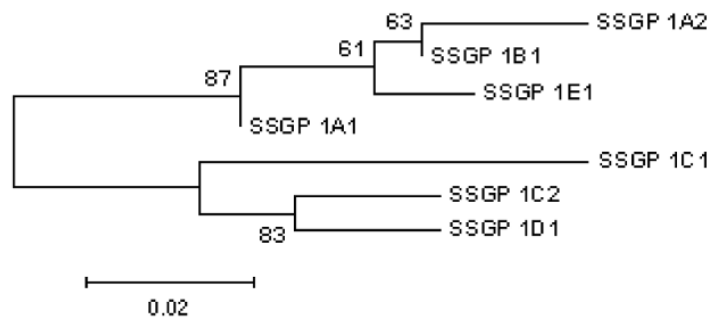

SPCRs

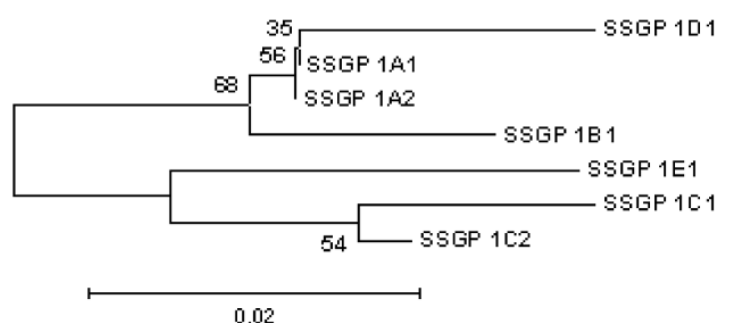

\section{3'-UTRs}

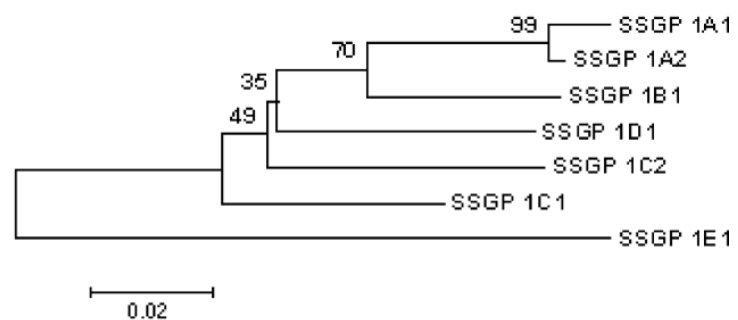

Figure 2 Phylogenetic tree for different regions of SSSGP-1 family members inferred using the Neighbor-joining method implemented in MEGA

pairing sites for interacting with micro-RNAs that may affect RNA stability or translation efficiency [48]. Multiple layers of gene regulation may be needed to ensure spatial and tissue-specific expression and prompt response of SSSGP-encoding genes to changes of host and other environmental conditions.
Functional division of SSSGPs: initiators and maintainers SSSGPs appear to have a division of labor, with "initiators" expressed only immediately after the start of feeding and "maintainers" expressed at later stages in the time course of feeding and plant response. Initiators, such as SSSGP-1C2 and SSSGP-1E in the SSSGP-1 family, were predominantly expressed in salivary glands (Figure $3 \mathrm{~A}$ ) at 


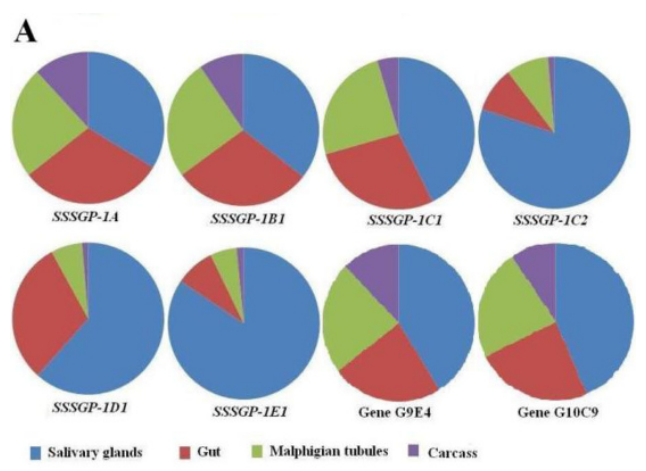

B
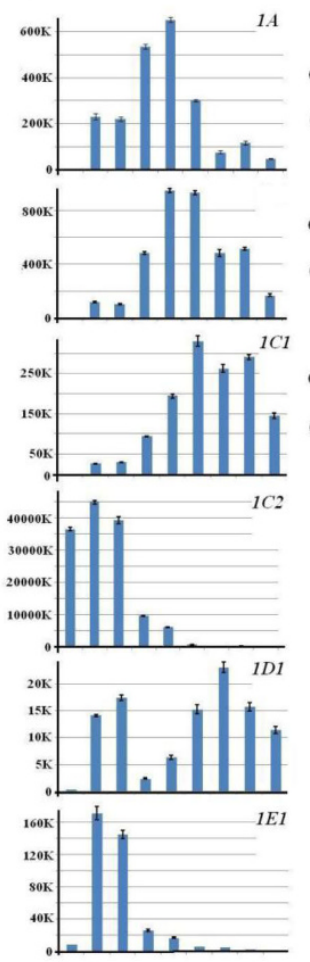

${ }_{3000 \mathrm{~K}} \mathrm{H} \quad \mathrm{G9E4}$
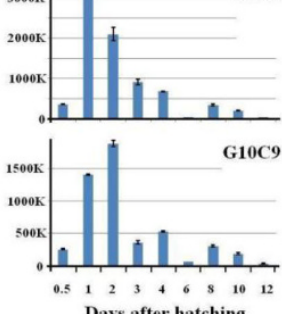

C
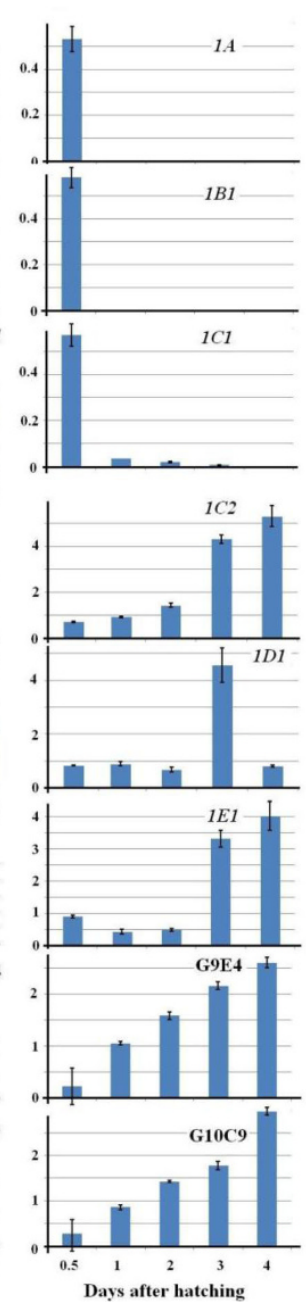

Figure 3 Distribution and abundance of transcripts corresponding to specific SSSGP-1 family members. A: Transcript distribution among tissues was determined using 3-day old biotype GP larvae. The remains after removing salivary glands, gut, and Malphigian tubules were designated as carcass. B: Transcript abundance in 0.5 to 12 -day old larvae on susceptible wheat plants (cultivar 'Newton'). C: Transcript abundance in 0.5 to 4-day old (dying) larvae on resistant wheat (cultivar 'Molly' containing H13 R-gene). Primer pairs and methods are shown in Additional file 8, Table S1. early stage of larval development (Figure 3B), and their expression was elevated at later time points in larvae feeding on resistant plants (Figure 3C). These observations are consistent with the postulation that initiators are secreted into plant tissue as effectors to manipulate plant cells. Hessian fly suppresses plant defense and induces the formation of nutritive cells within the first couple of days $[9,19]$. Once the insect has successfully manipulated host plants, one would expect that the expression of initiators is no longer needed. Indeed the manipulation of wheat seedlings is irreversibly achieved within the first few days following the Hessian fly initial attack [9]. The elevated expression of initiators in larvae feeding on resistant plants at later stages may reflect the fact that Hessian fly larvae continue to secret effectors to counter increased plant defense in these plants [21,22].

Maintainers, such as SSSGP-1A, SSSGP-1C1, and SSGP-1C1, were also expressed in other tissues besides the salivary glands (Figure 3A). The proteins produced in Malphigian tubules and carcass are unlikely to play a role in interaction with host plants, but could play a role in regulating Hessian fly symbiotic or associated microbes in insect tissues [49]. In addition, some SSSGPs could also play a role in regulating secondary microbial infection of the host tissues damaged at the feeding site [50]. The maintainers may possess antimicrobial activity, and are under selection pressure from changes in microbial populations. Further research on the network of these initiators and maintainers encoded by rapidly evolving genes will shed light on the biology and feeding behavior of gall midges.

\section{Conclusion}

In this study, we observed an unconventional conservation pattern in genes encoding SSSGPs in the Hessian fly. In the SSSGP-encoding genes, noncoding regions are highly conserved whereas regions coding for mature proteins are highly diversified. Rapid diversification in mature SSSGPs suggests that the genes are under selection pressure for functional adaptation. Considering the fact that most SSSGP-encoding genes are exclusively expressed in salivary glands, it is likely that rapid diversification in SSSGP-encoding genes is for the insect to counter changes in host plants for virulence. The conservation in the noncoding regions of these genes including introns also suggested potential mechanisms for sequence homogenization that are not yet fully understood. This report should be useful for future studies on genetic mechanisms involved in evolution and functional adaptation of parasite genes.

\section{Methods}

DNA libraries and sequencing

cDNA libraries and sequencing were as described previously $[23,24]$. A BAC library with $5 \times$ coverage was 
made from biotype GP Hessian fly larvae through a commercial contract with Amplicon Express (Pullman, WA). The BAC library contains inserts with average size of $\sim 150 \mathrm{kB}$ ligated into Hind III of pECBA1. A positive $\mathrm{BAC}$ clone, 10A23, was identified by screening the BAC library with a cDNA probe corresponding to the SSSGP$1 C 1$ gene. A shotgun library with average sizes of $1.5 \mathrm{kB}$ was made with 10 times coverage of the BAC clone 10A23, again through a commercial contract with Amplicon Express. The shotgun library was sequenced using ABI 3730 DNA analyzer at Kansas State University DNA sequencing facility. The shotgun sequences were assembled using Cap3 [51] and confirmed by PCR amplification and resequencing. The sequence of the whole BAC clone is $130 \mathrm{kB}$ and was deposited into Genbank with accession number GU196316. The $15 \mathrm{kB}$ cluster was located in the middle region toward 5'-end of the BAC.

\section{Quantitative real-time polymerase chain reaction (qRT- PCR) analysis}

RNA extraction, reverse-transcription and real-time PCR were carried out as described previously [24]. Two hundred larvae or tissues from 200 larvae were collected and pooled for RNA isolation for each replicate. Three biological replicates were included for each analysis. The ratio between abundances on resistant plants and the corresponding ones on susceptible plants were calculated. Primers used for PCR reactions are listed in Additional file 8, Table S1.

\section{Sequence analysis and comparison}

Sequence alignments and comparison were conducted using ClustalW [52]. For pairwise comparison, each sequence was compared with every other sequence. Scores for individual alignments are calculated based on the method of Wilbur and Lipman [53]. The higher the score is for a pairwise alignment, the higher the degree of conservation is between the two aligned sequences. Average scores were derived by dividing the sum of all pairwise scores with the number of alignments. Score range was the lowest score to the highest score among all pairwise alignments. For analysis of nucleotide substitutions, pair-wise alignments were obtained using ClusterW. Nonsynomonous $(d N)$ and synomonous $(d S)$ substitution ratios $(d N / d S)$ were obtained using PAML42 [54].

Phylogenetic trees were produced based on neighbor joining and maximum likelihood using MEGA4 [55].

\section{Southern blot analysis}

Hessian fly genomic DNA was isolated following a salting out protocol [56]. For Southern blot, $10 \mu \mathrm{g}$ of purified genomic DNA was digested with individual restriction enzymes. The digested DNA fragments were separated on a $0.8 \%$ agarose gel and blotted onto GeneScreen membrane (Perkin Elmer, Beltsville, MD). The membranes were then hybridized separately to individual probes of cDNAs from either the Hessian fly, or Asian rice midge, or wheat blossom midge. cDNA probes were produced with ${ }^{32} \mathrm{P}$ dCTP using a random labeling kit from Stratagene (La Jolla, CA). Hybridization was carried out overnight at $42^{\circ} \mathrm{C}$ in a plastic bag containing a $15-\mathrm{mL}$ hybridization solution, which consisted of $10 \%$ dextran sulfate, $1 \% \mathrm{SDS}, 1 \mathrm{M} \mathrm{NaCl}, \mathrm{pH}$ 8.0. After hybridization, the membranes were washed twice with $2 \times$ SSC at room temperature for $30 \mathrm{~min}$, twice with $2 \times \mathrm{SSC}(0.3 \mathrm{M}$ sodium chloride and $30 \mathrm{mM}$ tri-Sodium citrate dihydrate, $\mathrm{pH}$ 7.0) plus $1 \% \mathrm{SDS}$ at $65^{\circ} \mathrm{C}$ for $30 \mathrm{~min}$, and twice with $0.1 \times$ SSC plus $1 \%$ SDS at room temperature for $30 \mathrm{~min}$. Images were visualized by exposing the membranes to Kodak SR-5 X-ray film overnight.

\section{Additional material}

Additional file 1: Figure S1: Sequence alignments of different groups of SSSGP-encoding genes.

Additional file 2: Figure S2: Sequence alignments of different groups of SSSGP-encoding cDNAs.

Additional file 3: Figure S3: Evidence for clustered organization of SSSGP-encoding genes.

Additional file 4: Figure S4: Alignments of moderately diversified SSSGP group members (cDNAs).

Additional file 5: Figure S5: Evidence for single location of genes in the SSSGP-1 family.

Additional file 6: Figure S6: Sequence alignment of similar SSSGPencoding CDNAs (presumably derived from different alleles).

Additional file 7: Figure S7: Sequence alignment of cDNAs encoding ribosomal proteins.

Additional file 8: Table S1: Primers used for PCR reactions.

\section{Acknowledgements}

Mention of commercial or proprietary product does not constitute endorsement by the USDA. The authors thank Drs Frank White and Richard Beeman for reviewing an earlier version of the manuscript. Hessian fly voucher specimens (No. 150) are located in the KSU Museum of Entomological and Prairie Arthropod Research, Kansas State University, Manhattan, Kansas. This research was supported by USDA-ARS and a grant from USDA-NRI (2004-03099).

\section{Author details}

'USDA-ARS, Hard Winter Wheat Genetics Research Unit, 4008 Throckmorton Hall, Kansas State University, Manhattan, KS 66506, USA. ²Department of Entomology, Kansas State University, Manhattan, KS 66506, USA. ${ }^{3}$ Department of Biology, University College London, London NW12HE, UK. ${ }^{4}$ College of Life Sciences, Northwest A\&F University, Yangling, Shaanxi, China. ${ }^{5}$ USDA-ARS and Department of Entomology, Purdue University, West Lafayette, IN 47907, USA. ${ }^{6}$ Department of Plant Pathology, Washington State University, Pullman, WA 99164, USA.

\section{Authors' contributions}

MSC participated in sequence analysis and manuscript preparation. $\mathrm{XL}$ participated in library construction and sequence analysis. ZY involved in phylogenetic analysis and bioinformatics. HZ did real-time PCR analysis. RHS characterized CDNAs from rice midge and wheat midge. JJS and SH 
participated in data analysis and manuscript preparation. All authors have read and approved the final manuscript.

Received: 17 May 2010 Accepted: 28 September 2010

Published: 28 September 2010

\section{References}

1. Chapman RF: The insects: structure and function (Chapman eds.). Cambridge Univeristy press, Cambridge, UK, 4 1998, 12-36.

2. Miles PW: Aphid saliva. Biol Rev 1999, 74:41-85.

3. Tjallingii WF: Salivary secretions by aphids interacting with proteins of phloem wound responses. J Exp Bot 2006, 57:739-745.

4. Mutti NS, Pappan LK, Begum K, Pappan K, Chen M-S, Park Y, Reese JC, Reeck GR: A protein from the salivary glands of the pea aphid, Acyrthosiphon pisum, is essential in feeding on a host plant. Proc Natl Acad Sci USA 2008, 105:9965-9969.

5. Grant SR, Fisher EJ, Chang JH, Mole BM, Dangl JL: Subterfuge and manipulation: Type III effector proteins of phytopathogenic bacteria. Ann Rev Microbiol 2006, 60:425-449.

6. De Wit PJGM, Mehrab IR, Van den Burg HA, Stergiopoulo SI: Fungal effector proteins: past, present and future. Mol Plant Pathol 2009 10:735-747.

7. Kamoun S: A catalogue of the effector secretome of plant pathogenic oomycetes. Ann Rev Phytopathol 2006, 44:41-60.

8. Pate N, Hamamouch N, Li C, Hewezi T, Hussey RS, Baum TJ, Mitcchum MG Davis EL: A nematode effector protein similar to annexins in host plants. J Exp Bot 2010, 61:235-248.

9. Byers RA, Gallun RL: Ability of Hessian fly to stunt winter wheat. 1. Effect of larval feeding on elongation of leaves. J Econ Entomol 1972, 65:955-958.

10. Bede JC, Musser RO, Felton GW, Korth KL: Caterpillar herbivory and salivary enzymes decrease transcript levels of Medicago truncatula genes encoding enzymes in terpeniod biosynthesis. Plant Mol Biol 2006 60:519-531.

11. Musser RO, Hum-Musser SM, Eichenseer H, Peiffer M, Ervin G, Murphy JB, Felton GW: Herbivory: Caterpillar saliva beats plant defences. Nature 2002, 416:599-600.

12. Weech M-H, Chapleau M, Pan L, Ide C, Bede JC: Caterpillar saliva interferes with induced Arabidopsis thaliana defence responses via the systemic acquired resistance pathway. J Exp Bot 2008, 59:2437-2448.

13. Hori K: Insect secretions and their effect on plant growth. In Biology of Insect-Induced Galls. Edited by: Shorthouse JD, Rohfritsch D. Oxford University Press, New York; 1992:118-140.

14. Dieleman FL: Effect of gall midge infestation on plant growth and growth regulating substances. Ento Exp Appl 1969, 12:745-749.

15. Goethals K, Vereecke D, Jaziri M, Van Montagu M, Holsters M: Leafy gall formation by Rhodococcus fascians. Annu Rev Phytopathol 2001, 39:27-52.

16. Hatchett $\mathrm{JH}$, Starks KJ, Webster JA: Insect and mite pests of wheat. Wheat and Wheat improvement. Agronomy Monograph No 1987, 13:625-675.

17. Harris MO, Stuart JJ, Mohan M, Nair S, Lamb RJ, Rohfritsch O: Grasses and gall midges: plant defense and insect adaptation. Annu Rev Entomol 2003, 48:549-577.

18. Stuart JJ, Chen MS, Harris M: Hessian fly. In Genome Mapping and Genomics in Animals, Volume 1: Genome Mapping and Genomics in Arthropods. Edited by: Hunter, Kole. Springer, Berlin, Heidelberg, New York; 2008:93-100.

19. Harris MO, Freeman TP, Rohfritsch O, Anderson KG, Payne SA, Moore JA Virulent Hessian fly (Diptera: Cecidomyiidae) larvae induce a nutritive tissue during compatible interactions with wheat. Ann Entomol Soc Am 2006, 99:305-316.

20. Stuart JJ, Hatchett $\mathrm{JH}$ : Morphogenesis and cytology of the salivary gland of the Hessian fly, Mayetiola destructor (Diptera: Cecidomyiidae). Ann Entomol Soc Am 1987, 80:475-482.

21. Liu XL, Bai J, Huang L, Zhu L, Liu X, Weng N, Reese JC, Harris M, Stuart JJ, Chen MS: Gene expression of different wheat genotypes during attack by virulent and avirulent Hessian fly (Mayetiola destructor) larvae. J Chem Ecol 2007, 33:2171-2194.

22. Zhu L, Liu XM, Liu X, Jeannotte R, Reese JC, Harris M, Stuart JJ, Chen MS: Hessian fly (Mayetiola destructor) attack causes dramatic shift in carbon and nitrogen metabolism in wheat. Mol Plant-Microbe Interact 2008, 21:70-78.
23. Chen MS, Fellers JP, Stuart JJ, Reese JC, Liu XM: A group of related CDNAs encoding secreted proteins from Hessian fly [Mayetiola destructor (Say)] salivary glands. Insect Mol Biol 2004, 13:101-108.

24. Chen MS, Zhao HX, Zhu YC, Scheffler B, Liu XM, Liu X, Hulbert S, Stuart JJ: Analysis of transcripts and proteins expressed in the salivary glands of Hessian fly (Mayetiola destructor) larvae. J Insect Physiol 2008, 54:1-16.

25. Bennett J, Bentur JS, Pasalu IC, Krishnaiah K: New approaches to gall midge resistance. Proceedings of the International Workshop Hyderabad, India 2004, 1-23, 22-24 November 1998

26. Calvo E, Mans BJ, Andersen JF, Ribeiro MC: Function and evolution of a mosquito salivary protein family. J Biol Chem 2006, 281:1935-1942.

27. Olivera BM, Rivier J, Clark C, Ramilo CA, Corpuz GP, Abogadie FC, Mena EE, Woodward SR, Hillyard DR, Cruz LJ: Diversity of conus neuropeptides. Science 1990, 249:257-263.

28. Lehmann AR: New functions for $\mathrm{Y}$ family polymerases. Mol Cell 2006 24:493-495.

29. Hughes AL, Nei M: Pattern of nucleotide substitution at major histocompatibility complex class I loci reveals overdominant selection. Nature 1998, 335:167-170

30. Tanaka R, Nei M: Positive Darwinian selection observed at the variableregion genes of immunoglobulins. Mol Biol Evol 1989, 6:447-459.

31. Hughes $A L$, Yeager M: Coordinated amino acid changes in the evolution of mammalian defensins. J Mol Evol 1997, 44:675-682.

32. Michelmore RW, Meyers BC: Clusters of resistance genes in plants evolve by divergent selection and a birth-and-death process. Genome Res 1998 8:1113-1130

33. Bishop JG, Dean AM, Mitchell-Olds T: Rapid evolution in plant chitinases: Molecular targets of selection in plant-pathogen coevolution. Proc Natl Acad Sci USA 2000, 97:5322-5327.

34. Morgan W, Kamoun S: RXLR effectors of plant pathogenic oomycetes. Curr Opin Microbiol 2007, 10:332-338.

35. Boller T, He SY: Innate immunity in plants: An arms race between pattern recognition receptors in plants and effectors in microbial pathogens. Science 2009, 324:742-744.

36. Burdon JJ, Thrall PH: Coevolution of plants and their pathogens in natural habitats. Science 2009, 324:755-756.

37. Bent AF, Machey $D$ : Elicitors, effectors and $R$ genes: The new paradigm and a lifetime supply of questions. Annu Rev Phytopathol 2007, 45:399-436.

38. Dover GA: Molecular drive: a cohesive mode of species evolution. Nature 1982, 199:111-117

39. Liao D: Concerted evolution. In Nature Encyclopedia of the Human Genome. Edited by: Cooper DN. Nature Publishing Group, London; 2003:1:938-942.

40. Hilliker AJ, Harauz G, Reaume AG, Gray M, Clark SH, Chovnick A: Meiotic gene conversion tract length distribution within the rosy locus of Drosophila melanogaster. Genetics 1994, 137:1019-1026.

41. Cromie GA, Hyppa RW, Cam HP, Farah JA, Grewal SI, Smith GR: A discrete class of intergenic DNA dictates meiotic DNA break hotspots in fission yeast. PLoS Genet 2007, 3:e141.

42. Mézard C: Meiotic recombination hotspots in plants. Biochem Soc Trans 2006, 34:531-534.

43. Steiner WW, Steiner EM, Girvin AR, Plewik LE: Novel nucleotide sequence motifs that produce hotspots of meiotic recombination in Schizosaccharomeces prombe. Genetics 2009, 182:459-469.

44. Jeffreys AJ, May CA: Intense and highly localized gene conversion activity in human meiotic crossover hot spots. Nat Genet 2004, 36:151-156.

45. Hurst LD, Smith GC: The evolution of concerted evolution. Proc $R$ Soc Lond B 1998, 265:121-127.

46. Black BL, Lu J, Olson EN: The MEF2A 3' untranslated region functions as a cis-acting translational repressor. Mol Cell Biol 1997, 17:2756-2763.

47. Di Liegro CM, Bellafiore M, Izquierdo JM, Rantanen A, Cuezva JM: 3'untranslated regions of oxidative phosphorylation mRNAs function in vivo as enhancers of translation. Biochem J 2000, 15:109-115.

48. He L, Hannon GJ: MicroRNAs: small RNAs with a big role in gene regulation. Nat Rev Genet 2004, 5:522-531.

49. Bourtzis K, Miller TA: Insect Symbiosis. CRC Press/Taylor \&Francis, New York $2006,2 \cdot 1-276$

50. Boosalis GM: Hessian fly in relation to the development of crown and basal stem rot of wheat. Phytopathol 1954, 44:224-229. 
51. Huang X, Madan A: CAP3: A DNA sequence assembly program. Genome Res 1999, 46:37-45.

52. Chenna R, Sugawara H, Koike T, Lopez R, Gibson TJ, Higgins DG, Thompson JD: Multiple sequence alignment with the Clustal series of programs. Nucl Acid Res 2003, 31:3497-3500.

53. Wilbur WJ, Lipman DJ: Rapid similarity searches of nucleic acid and protein data banks. Proc Natl Acad Sci USA 1983, 80:726-730.

54. Yang Z: PAML 4: Phylogenetic analysis by maximum likelihood. Mol Biol Evol 2007, 24:1586-1591.

55. Tamura K, Dudley J, Nei M, Kumar S: MEGA4: Molecular evolutionary genetics analysis (MEGA) software version 4.0. Mol Biol Evol 2007 24:1596-1599.

56. Chen MS, Liu X, Zhu YC, Reese JC, Wilde GE: Genes encoding a group of related small secreted proteins from the gut of Hessian fly larvae [Mayetiola destructor (Say)]. Insect Sci 2006, 13:339-348.

doi:10.1186/1471-2148-10-296

Cite this article as: Chen et al:: Unusual conservation among genes encoding small secreted salivary gland proteins from a gall midge. $B M C$ Evolutionary Biology 2010 10:296.

\section{Submit your next manuscript to BioMed Central} and take full advantage of:

- Convenient online submission

- Thorough peer review

- No space constraints or color figure charges

- Immediate publication on acceptance

- Inclusion in PubMed, CAS, Scopus and Google Scholar

- Research which is freely available for redistribution

Submit your manuscript at www.biomedcentral.com/submit 